\title{
Toxicity of Alum to Newzealand Rabbits
}

\author{
Medani, A. B., El Badwi, S. M. A. and Amin, A. E. \\ 1. Department of Pharmacology and Toxicology, The Nile College, Khartoum,Sudan. \\ 2. Dept. of Medicine, Pharmacology and Toxicology, P.O.Box11111, University of Khartoum, Khartoum, Sudan.
}

\begin{abstract}
This study was considered to assess the risk of alum which is used in Sudan for drinking water treatment purposes for a long period without toxicity freedom records .Newzealand rabbits were chosen for animal phase trials, divided into 3 groups. One group was the undosed controls. Test groups were given alum at dose rates of $1 \%$ and $20 \%$ respectively for two groups after an adaptation period. Clinical signs were observed together with postmortem and histopathological examinations. Chemical investigations included enzymatic, metabolic, electrolyte and hematological changes. The test rabbits demonstrated low voice, inappitence, whitish salivation, watery diarrhea and recumbence followed by emphysematous, lungs, electrolyte imbalance, renal dysfunctions, stiff focal inflammation of the empty intestines and congested liver with white spots. The control group was normal .On atomic absorption only the lungs kept residual alum, while the livers washed- out the substance ,may be via bile. Alum -dosed rabbits showed necrosis in the cortex and medulla of the kidney, emphysema in the lungs and necrosis in the hepatocytes. On evaluation of the above results, alum was considered to be toxic to Newzealand rabbits at dose rates tried.
\end{abstract}

Key words: Toxicity, alum, Newzealand, rabbits.

\section{Introduction}

Aluminium sulphate is the world's most abundant material. It makes up to 7.9 percent of the Earth's crust by weight and is naturally found in water. It was first used at the beginning of the twentieth century as a water coagulant for colour and turbidity removal and as an integral part of the multibarrier approach to drinking water treatment for the aim of protection from some life threatening diseases and making water more palatable. It is preferred by many water utility mangers for its effectiveness, availability, purity and cost. The amount of alum taken from drinking water is nearly 0.I percent of the total intake of aluminum. 99.9 percent of the ingested aluminum is excreted though normal bowl functions [1], because its acidity is naturalized in the duodenum and thus most of the aluminum is precipitated and not absorbed into blood. In some individuals, the long term accumulation of aluminum may lead to a dementia due to the formation of a myeloid protein disposition that is similar to those of

Corresponding author: Amna Beshir Medani Ahmed. Department of Pharmacology and Toxicology, The Nile College, Khartoum,Sudan.
Alzheimer's disease.

\section{Methods and Material}

\subsection{Method}

\subsubsection{Haematological Methods}

These were described by Schalm [2] .Blood samples from both goats and rabbits were collected into clean dry bottles containing the anti-coagulant heparin from the jugular vein and the ear vein respectively.

\subsubsection{Hb (Haemglobin) Concentration}

The concentration of haemoglobin was determined by the cynomethaemoglobin technique the method is based on the conversion of haemoglobin by Drabkins solution $(0.2 \mathrm{~g}$ potassium cyanide, $0.2 \mathrm{~g}$ potassium ferricyanide and $1 \mathrm{~g}$ sodium bicarbonate per litre of distilled water) to cyanomethaemoglobin. The haemoglobin concentration was estimated in $\mathrm{g} / \mathrm{dl}$ of blood.

\subsubsection{PCV (Packed Cell Volume)}

Fresh blood samples were centrifuged in a micro haematocrit centrifuge (Hawksley and Sons Ltd. England) for 5 minutes packed cell volume percent was 
read off on the scaling instrument provided with the centrifuge.

\subsubsection{RBC (Red Blood Cell) Count}

Red blood cells were counted with an improved Neubauer haemocytometer (Hawksley and Sons Ltd., England). Formal citrate was used as a diluent.

\subsubsection{Histological Methods}

The specimens were collected immediately after death or slaughter and fixed in $10 \%$ formal saline, embeded in paraffin wax, sectioned at $5 \mu \mathrm{m}$ and stained with haemotoxylin and eosin ( $\mathrm{H} \& \mathrm{E}$ ) using Mayer's haemalum.

\subsubsection{Chemical Methods}

Blood samples obtained from the jugular vein of goats before and after dosing with $\mathrm{AlSO}_{4}$. Venous blood samples were centrifuged at 3000 r.p.m. for 5 minutes and stored at $-20^{\circ} \mathrm{C}$ until analyzed for LDH, GOT, ALP, CK, Cholesterol, Creatinine, total bilirubin, urea, total protein, calcium ,albumin, phosphorus, iron and magnesium by a colorimetric method using a commercial kit (Randox Laboratories Ltd., U.K).

\subsubsection{Determination of $\mathrm{Na}^{+}$and $\mathrm{K}^{+}$}

Flame or Atomic emission, using Bio-dynamics Lyteteck Flame Photometer, USA.

\subsection{Procedure}

Dilution of the sample in 100 by distilled water compared with $\mathrm{Na}$ and $\mathrm{K}$ standard (Sherwood Scientific Ltd. UK) with concentration of 140 and 50 $\mathrm{mmol} / \mathrm{l}$ respectively).

\subsubsection{Determination of $\mathrm{Al}$}

Preparation of $\mathrm{Al}$ standard solution I gm of $\mathrm{Al}$ wire was dissolved in $1 \mathrm{ml} \mathrm{HCl}$, then diluted to 1 litre with $1 \%$ $\mathrm{NaCl}$. From the $1000 \mathrm{ppm}$ solution transfer $5 \mathrm{ml}$ into $100 \mathrm{ml}$ beaker, add the brine solution and shake well ending into serial dilutions for calibration.

Reagents for $\mathrm{Al}$ These were six reagents, Calcium chloride, prepared from $\mathrm{CaCo}_{3}$ and $\mathrm{HCl} 10 \%$ Hydroxylamine Hydrochloride ; $0.75 \%$ Pottassium ferricyride; 4\% Thiogollic Acid (Mercuptic Acid);
Sodium acetate; acetic acid buffer solution and $05 \%$ Alizarin Red solution.

2.2.2 Preparation of the sample

Weigh $1 \mathrm{gm}$ of lung tissue into a tefler beaker add 30 $\mathrm{ml}$ of $6 \mathrm{~N}-\mathrm{Nacl}$, seal the cover properly and put it on a low hot plate to dissolve. After venting, add $10 \mathrm{ml}$ of white spirit (petroleum ether) to extract the fats, shake well, filter into $500 \mathrm{ml} \mathrm{v}$-flask. Transfer $5 \mathrm{ml}$ into 100 ml v-flask. (Microwave Accelerated Reaction System, MARS).

\subsection{Protocol}

Add sample, standards and 2,1,1,2,10 and $10 \mathrm{ml}$ of the blank to the aforesaid reagents respectively. Sample color was then read in the KAL/L Milton RO 4 Spectoronic 1001 C (Scientific Technical Supplies, UK) at $475 \mathrm{~nm}$.

\subsection{Statistical Methods}

The difference between mean values of data were analysed by the un-paired students- t-test [3].

\subsection{Animals}

Nine 5-7 month old mixed Newsealand rabbits were purchased from Balsam Pharmaceutical Laboratories, Khartoum North and housed in cages $\left(4 \mathrm{~m}^{2}\right.$ for each dose-group) within the premises of the Department of Parasitology, Faculty of Veterinary Medicine, University of Khartoum. Animals were clinically healthy and were given prophylactic doses of oxytetracycline 5\% (Bremerpharma, Germany) and sulphamethazine $33.3 \%$ (Norbrook, U.K.) against bacterial infections and coccidiosis respectively. The animals were ear-tagged and allowed a 2-week preliminary period during which time lucerne and drinking Nile water were provided ad libitum.

\subsection{Administration of the Doses}

Stock materials were prepared of $1 \%$ and $20 \%$ solutions of $\mathrm{ALSO}_{4}$. Rabbits of the control group were given the untreated Nile water ad libitum. 


\subsection{Parameters}

Clinical signs and mortality rates were recorded. Blood samples were obtained from the jugular vein before the start of the experimental dosing and there after fortnightly for haematological investigations and serum analysis.

$\mathrm{Hb}$ concentration (Haemoglobin), PCV (packed cell volume), RBC (red blood cell) and WBC (white blood cell) counts were estimated.

Sera were analyzed for the activities of ALP, AST, CK, GPT and LDH and also for the concentrations of cholesterol, creatinine, bilirubin, uric acid, urea, albumin, total protein, glucose, calcium, inorganic phosphorus, iron, sodium and potassium.

\subsection{Effect of $1 \%$ Alum in Drinking Water on Newzealand Rabbits}

\subsubsection{Clinical Signs and Mortality Rates}

Newzealand rabbits (group 2) showed inappetance, nervous signs and were finally recumbent and the mortality rate was 100 percent. A normal behavior was characteristic for group 1 rabbits of the undosed controls.

\subsection{Post-mortem Changes}

Empty intestines were the most prominent feature. Stiffness of lungs was also pronounced in addition the presence of white foci the intestines and livers. A normal scene was observed in the control group.

\subsection{Histo-pathological Picture}

Oedema and emphysema were obvious in lungs, intestines suffered from catahrral inflammation (Fig.1) and in the livers, generalized necrosis and lympthocyte infiltration were very clear. Normal organ pictures were clear in the control rabbits.

\section{Results and Discussion}

\subsection{Clinical Signs and Mortality Rate}

The uncontrolled diarrhoea, uncontrolled salivation, dullness, shivering, inappitance and finally recumbence (Fig. 2) were the most obvious sings in rabbits of (group 3) with a mortality rate of 100 percent. No abnormality in behavior was observed in the control rabbits.

\subsection{Post Mortem Changes}

Intestines and livers were spotted with white foci and lungs were stiff and greenish, where as group 1 rabbits showed a normal picture.

\subsection{Histo-pathological Picture}

Lung sections of the $20 \%$ alum -dosed group of rabbits showed emphysema and the intestines were edematous with catarrhal inflammation, hearts slightly necrotic, spleens slightly congested and the liver showed degenerative necrosis and lymphocytic infiltration. The control rabbits showed a normal picture.

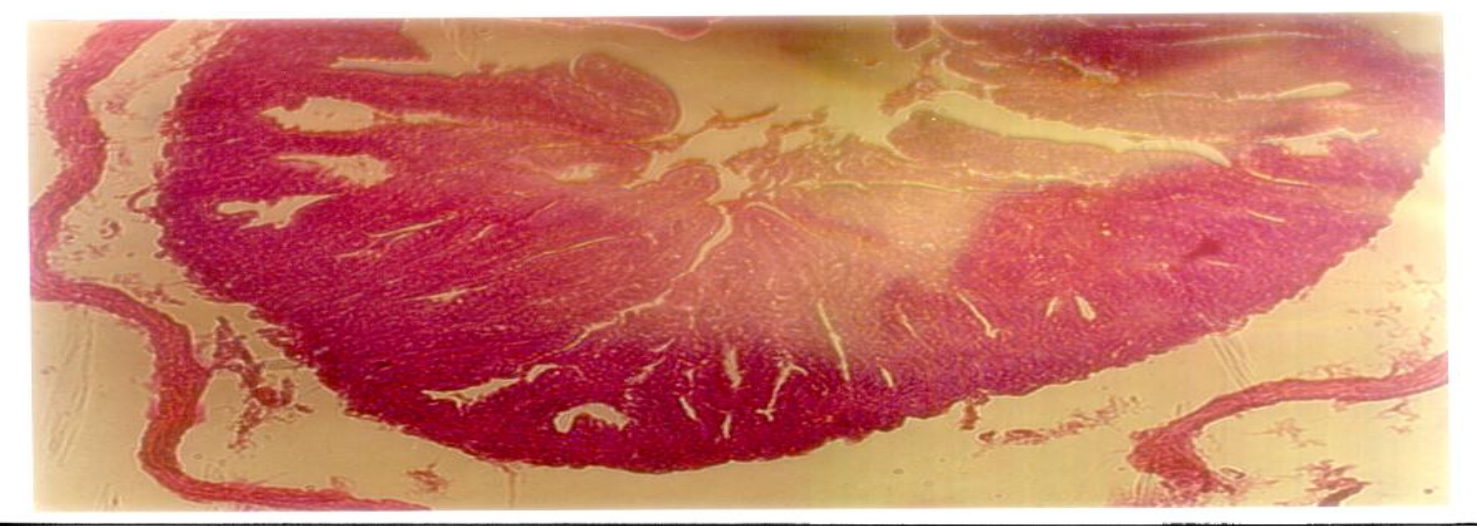

Fig. 1 Catahrral Inflammation Of the Intestines of $1 \%$ alum -dosed Rabbits Effect of $20 \%$ alum in drinking water on Newzealand rabbits 


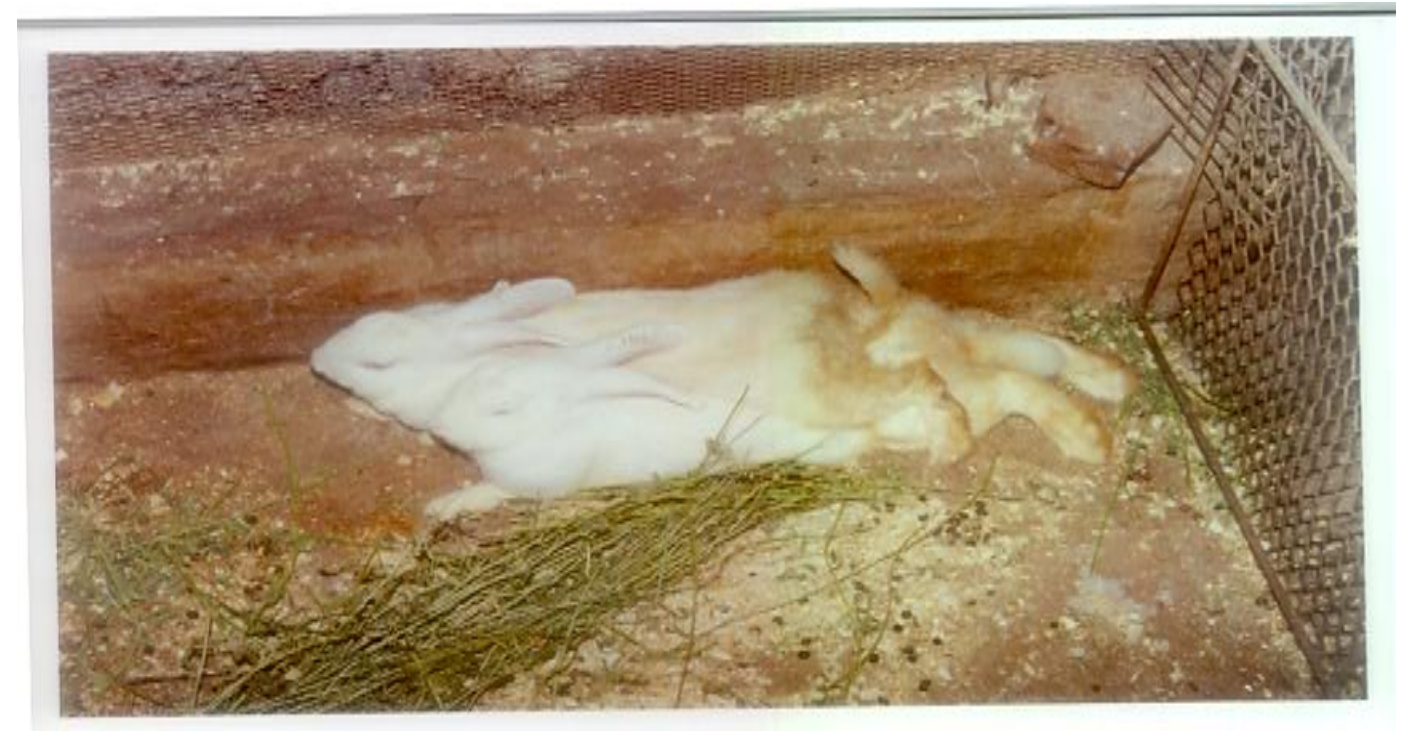

Fig. 2 Recumbency in Newzealnd Rabbits Intoxicated with $20 \%$ alum.

\subsection{Fluctuations in Serum Enzymes}

Serum levels of ALP, CK, and GPT in rabbits of both test groups decreased $(\mathrm{P}<0.05-0.01)$ in comparison to the un-dosed control group, whereas test groups concentrations of GOT and LDH showed obvious increases $(\mathrm{P}<0.05-0.01)$. Normal readings were obtained from the un-dosed control group.

\subsection{Change in Serum Metabolites}

Both test groups evaluated for uric acid and glucose levels showed non-significant changes $(\mathrm{P}>0.05)$ compared to the control group. Also when both test groups were evaluated for creatinine and cholesterol levels, non-significant changes were detected for the group dosed with $1 \%$ alum whereas the group dosed with 20\% alum manifested significant $(\mathrm{P}<0.05)$ increases compared to the control group. Test groups bilirubin values were highly $(\mathrm{P}<0.001)$ increased in comparison to the control group. Urea and total protein concentrations of the group dosed with $1 \%$ alum increased significantly $(\mathrm{P}<0.05)$ whereas the albumin value of the same group decreased insignificantly $(\mathrm{P}<$ $0.05)$ in comparison to the control. Urea and albumin of the group dosed with $20 \%$ alum showed significant (P $<0.01)$ respective increased and decreased values in comparison to the control group, while the total protein value increased insignificantly $(\mathrm{P}>0.05)$. Acceptable Newzealand rabbit normal values of the serum metabolites were obtained from the un-dosed group.

\subsection{Changes in Serum Electrolytes}

Both test groups showed significantly decreased values $(\mathrm{P}<0.05-0.01)$ in magnesium, iron, sodium, potassium, calcium, and phosphorus when compared to the control group which showed normal electrolyte values.

\subsection{Hematological Values}

Both groups showed serum intensities of $\mathrm{Hb}$ that were similar $(\mathrm{P}>0.05)$ to the levels obtained from the control group. Both groups also highlighted significant $(\mathrm{P}<0.05-0.01)$ decreases of PCV, RBCs and WBCs values compared to those of the untreated control rabbits. Control hematological values were normal.

\subsection{Concentrations of alum in the Vital Organs of} Newzealand Rabbits

The average atomic absorption values and relevant concentrations of alum in the lungs and livers of Newzealand rabbits were shown in Table 5. Average absorbance in the livers was zero . 
Table 1 Average values (mean \pm SD) of serum enzymes of the alum-dosed rabbits.

\begin{tabular}{llllll}
\hline Group/dose & ALP (iu/l) & GOT (iu/l) & CK (iu/l) & GPT (iu/l) & LDH (iu/l) \\
\hline $\mathbf{G}_{\mathbf{1}}$ & $16.03 \pm 48.43$ & $22.61 \pm 2.67$ & $24.70 \pm 0.06$ & $12.72 \pm 1.84$ & $46.72 \pm 1.77$ \\
$\mathbf{G}_{2}$ & $15.27 \pm 34.70^{*}$ & $45.90 \pm 5.3^{*}$ & $15.00 \pm 0.05^{*}$ & $8.83 \pm 0.06^{*}$ & $106.47 \pm 12.39^{*}$ \\
$\mathbf{G}_{3}$ & $11.21 \pm 5.20^{* *}$ & $45.9 \pm 5.9^{*}$ & $16.20 \pm 0.03^{* *}$ & $10.6 \pm 0.03^{*}$ & $21.2 \pm 0.00^{* *}$ \\
\hline
\end{tabular}

* denotes $\mathrm{P}<0.05$ ** denotes $\mathrm{P}<0.01$.

Table 2 Average values (mean \pm SD) of serum metabolites of the alum-dosed rabbits.

\begin{tabular}{|c|c|c|c|c|}
\hline Group/dose & Albumin & Urea & Total protein & Cholesterol \\
\hline$\overline{\mathbf{G}_{1}}$ & $3.85 \pm 0.04$ & $30.35 \pm 0.69$ & $4.99 \pm 0.13$ & $62.37 \pm 5.26$ \\
\hline $\mathbf{G}_{2}$ & $2.73 \pm 0.51^{\mathrm{N} . S}$ & $39.33 \pm 3.21^{*}$ & $6.03 \pm 0.31^{*}$ & $112.33 \pm 30.37^{\text {N.S }}$ \\
\hline $\mathbf{G}_{3}$ & $2.57 \pm 0.15^{* * *}$ & $39.67 \pm 1.15^{* *}$ & $5.63 \pm 0.65^{\mathrm{N} . \mathrm{S}}$ & $133.00 \pm 26.06^{*}$ \\
\hline Group /Dose & Bilirubin & \multicolumn{2}{|c|}{ Glucose } & Creatinine \\
\hline G control & $0.12 \pm 0.04$ & \multicolumn{2}{|c|}{$81.13 \pm 1.54$} & $1.38 \pm 0.01$ \\
\hline G 1 & $0.76 \pm 0.30^{* * *}$ & \multicolumn{2}{|c|}{$97.00 \pm 17.69^{\text {N.S }}$} & $1.07 \pm 0.14^{\mathrm{N} . \mathrm{S}}$ \\
\hline G 2 & $0.68 \pm 0.27^{* * *}$ & \multicolumn{2}{|c|}{$115.67 \pm 32.88^{\mathrm{N} . S}$} & $0.95 \pm 0.13^{*}$ \\
\hline
\end{tabular}

NS $=$ Not significant $*$ denotes $\mathrm{P}<0.05 *$ denotes $\mathrm{P}<0.01 * * *$ denotes $\mathrm{P}<0.001$.

Table 3 Average values (mean \pm SD) of serum electrolytes of the alum-dosed rabbits.

\begin{tabular}{lllllll}
\hline Group /Dose & $\mathbf{M g}(\mathbf{m g} / \mathbf{d l})$ & Iron $(\boldsymbol{\mu g} / \mathbf{d l})$ & $\mathbf{N a}(\mathbf{m g} / \mathbf{d l})$ & $\mathbf{K}(\mathbf{m g} / \mathbf{d l})$ & $\mathbf{C a}(\mathbf{m g} / \mathbf{d l})$ & $\mathbf{P}(\mathbf{m g} / \mathbf{d l})$ \\
\hline $\mathbf{G}_{\mathbf{1}}$ & $1.56 \pm 0.17$ & $256.23 \pm 39.81$ & $77.00 \pm 32.26$ & $1.97 \pm 0.12$ & $11.38 \pm 0.10$ & $4.34 \pm 0.13$ \\
$\mathbf{G}_{2}$ & $0.36 \pm 0.11^{* *}$ & $34.67 \pm 2.90^{* *}$ & ND & ND & $2.83 \pm 0.22^{* *}$ & $1.29 \pm 0.58^{*}$ \\
$\mathbf{G}_{3}$ & $0.41 \pm 0.02^{* *}$ & $30.45 \pm 6.60^{* *}$ & ND & ND & $3.33 \pm 0.20^{* *}$ & $1.13 \pm 0.98^{*}$ \\
\hline
\end{tabular}

$\mathrm{ND}=$ Not determined $*$ denotes $\mathrm{P}<0.05 *$ denotes $\mathrm{P}<0.01$.

Table 4 Average haematological values (mean \pm SD) of the alum -dosed rabbits.

\begin{tabular}{|c|c|c|c|c|}
\hline Group /Dose & $\mathrm{Hb}(\mathrm{g} \%)$ & PCV \% & $\operatorname{RBCs}\left(\times 10^{6}\right)$ & WBCs $\left(\times 10^{3}\right)$ \\
\hline$\overline{\mathbf{G}_{1}}$ & $10.92 \pm 0.83$ & $35.54 \pm 4.33$ & $3.79 \pm 0.29$ & $3.86 \pm 0.29$ \\
\hline $\mathbf{G}_{2}$ & $7.93 \pm 6.92^{\mathrm{N} . S}$ & $29.60 \pm 1.83^{*}$ & $7.40 \pm 2.96^{* *}$ & $11.77 \pm 3.99^{* *}$ \\
\hline $\mathbf{G}_{3}$ & $11.67 \pm 1.17^{\mathrm{N} . S}$ & $26.80 \pm 1.10^{* *}$ & $10.53 \pm 5.09^{* *}$ & $13.57 \pm 2.2 .3^{* *}$ \\
\hline
\end{tabular}

NS=Not significant $*$ denotes $\mathrm{P}<0.05 *$ denotes $\mathrm{P}<0.01$.

Table 5 Average concentrations of $\mathrm{Al} 2\left(\mathrm{SO}_{4}\right)_{3}$ in the lungs and livers of Newzealand rabbits dosed with $20 \%$ alum in drinking water.

\begin{tabular}{llll}
\hline Organ & Days dosed & Absorbance* & Concentration ppm \\
\hline Lung & 5 & 0.011 & 3.395 \\
Lung & 9 & 0.024 & 7.41 \\
Liver & 5 & 0.00 & 0.00 \\
Liver & 9 & 0.00 & 0.00 \\
\hline
\end{tabular}

*Blank of $50 \mathrm{ppm}$ read at $475 \mathrm{~nm}$. , absorbs at 0.162 .

\subsection{Approval of Toxicity of Alum to Newzealand Rabbits}

In addition to the shouting mortality rates, all alum-dosed rabbits, to varying extents with dose rates, showed inappetance, uncontrolled diarrhea and salivation, dullness, shivering, nervous signs ,motor and behavioral disturbances and finally [4, 5] .All these results indicates an anticholinesterase activity of alum. The anaemia and depletion were mainly indicated by the decrease in PCV, RBCs and WBCs.This can be a result of renal dysfunction [6]. The decrease in ALP 
suggests that alum interferes with excretory ability of the liver cells [7, 8]. The highly observable decrease in electrolytes may explain the previously mentioned clinical, post-mortem and histopathological signs. The increased creatinine is suggestive of renal dysfunction.

\section{Conclusion}

Alum percentages used in drinking water treatment utilities should be reduced into values less than $1 \%$.

More specialized research in the area of Alzheimer disease is needed.

Other alternative substances that can be effective on its own or in combination with other ones should be founded.

Work health precautions for workers in the fields that enforce direct contact with alum and/or its derivatives should be revised in parallel to improvement of research in alum.

Periodic clinical investigations to people supplied with drinking water treated with alum .

Record of affected patients in specific projects will surely improve research and invention of drugs to treat them is a must.

Improvement of awareness about the toxicity of alum will help a lot in avoiding its effects, especially in rural areas where laymen use alum at home for different purposes increasing the exposure and hence the possibility of toxicity.

\section{References}

[1] Stauber, J. L., Florence, T. M., Davies, C. M., Adams, M. S., and Buchanan, S. J. 1999. "Bioavailability of $\mathrm{Al}$ in alum-Treated Drinking Water." JAWWA 91 (11): 84-93.

[2] Schalm, O. W. 1965. Minutes of the Regents of the University of California http://dynaweb.oac.cdlib.org:8088/dynaweb/uchist/public /regentminutes/regents865/@Generic_BookTextView/, 111.

[3] Snedecor, G. W., and Cochran, W. G. 1989. Statistical Methods, Eighth Edition. Iowa State University Press.

[4] First Conference on Metabolism of Trace Elements Related to Human Diseases. 1986. Acta Pharmacologica et Toxicologica. SupplementVII.Norway.

[5] MSDS (Material Saftey Data Sheet). 2007. Aluminium-induced Osteomalacia. www.proliberty.com/observer/20071207.htm.

[6] Yuan, B.,Klein, M. H. ,Contiqualia, R. S.,Mishell, J. L. ,Seligman, P. A., Miller, N. L., Molitoris, B.A.,Alfrey A.C. and Shapiro J. I. 1989. "The Role of Aluminium in the Pathogenesis of Anemia in an Outpatient Hemodialysis Population." Pubmed 11 (2-3): 91-6.

[7] Hodsman, S., and Alfrey, A. C. 1982. Elevated Aluminium Levels in Patients Undergoing HeModialysis. J. Clin. Endocrine. Metab. 54: 539-45.

[8] Mailboux, R. J., Lemire, J. and Appanna, V. D. 2011. "Hepatic Response to Aluminium toxicity : Dyslipidemia and Liver Diseases.” Exp. Cell Res. 317 (16): 2231-8. 